\title{
Pesticide safety training and practices in women working in small-scale agriculture in South Africa
}

S Naidoo, L London, H-A Rother, et al.

Occup Environ Med 2010 67: 823-828 originally published online June 24, 2010

doi: 10.1136/oem.2010.055863

Updated information and services can be found at:

http://oem.bmj.com/content/67/12/823.full.html

These include:

References This article cites 29 articles, 5 of which can be accessed free at: http://oem.bmj.com/content/67/12/823.full.html\#ref-list-1

Email alerting Receive free email alerts when new articles cite this article. Sign up in the service box at the top right corner of the online article.

Notes

To request permissions go to:

http://group.bmj.com/group/rights-licensing/permissions

To order reprints go to:

http://journals.bmj.com/cgi/reprintform

To subscribe to BMJ go to:

http://journals.bmj.com/cgi/ep 


\title{
Pesticide safety training and practices in women working in small-scale agriculture in South Africa
}

\author{
S Naidoo, ${ }^{1}$ L London, ${ }^{2}$ H-A Rother, ${ }^{2}$ A Burdorf, ${ }^{3}$ R N Naidoo, ${ }^{1}$ H Kromhout ${ }^{4}$
}

- An Additional table is published online only. To view this file please visit the journa online (http://oem.bmj.com).

1 Department of Occupational and Environmental Health, School of Family and Public Health Medicine, Nelson R Mandela School of Medicine, University of KwaZulu-Natal, Durban, South Africa

${ }^{2}$ Centre for Occupational and Environmental Health Research, School of Public Health and Family Medicine, University of Cape Town, Cape Town, South Africa

${ }^{3}$ Department of Public Health, Erasmus MC, University Medical Center Rotterdam, Rotterdam, the Netherlands

${ }^{4}$ Institute for Risk Assessment Sciences, Environmental Epidemiology Division, Utrecht University, Utrecht, the Netherlands

\section{Correspondence to}

Dr Saloshni Naidoo, Department for Occupational and Environmental Health, Nelson R Mandela School of Medicine, University of KwaZulu-Natal, Private Bag 7 Congella 4013, South Africa;

naidoos71@ukzn.ac.za

Accepted 4 March 2010 Published Online First 24 June 2010

\section{ABSTRACT}

Objectives Unregulated use of pesticides continues in developing countries in the presence of illiteracy and limited safety training and practices. This paper describes training and safety practices when mixing and spraying pesticides, and acetylcholinesterase levels among women farmers in KwaZulu-Natal, South Africa. Methods A cross-sectional study conducted in women working in small-scale agriculture in rural KwaZulu-Natal, South Africa in 2006 assessed pesticide training and safety practices using a questionnaire survey and measured acetylcholinesterase levels in 803 women. Three components of safety behaviour were identified through principle component analysis and described.

Results The mean age of participants was 41.8 years (range 18-82 years) with a mean of 6.9 years (range $1-12$ years) of education among school attendees. Among the 803 women included, 366 (45.6\%) were the primary sprayers on their farm. Only $16.4 \%$ of the sprayers had ever attended a pesticide training course and only $18.0 \%$ reported ever reading pesticide labels. Of the women using some form of protective equipment, $56.7 \%$ and $54.9 \%$ reported doing so when mixing and spraying pesticides, respectively. The mean acetylcholinesterase level corrected for haemoglobin among study participants was $28.9 \mathrm{U} / \mathrm{g} \mathrm{Hb}$ (95\% Cl 28.4 to 29.4).

Conclusion Women working in small-scale agriculture in rural KwaZulu-Natal with limited access to pesticide training observe few safety practices when mixing and spraying pesticides.

\section{INTRODUCTION}

In developing countries, the majority of women work in agriculture ${ }^{1}$ or live in agrichemical exposed settings. They are exposed to pesticides domestically through washing the pesticide contaminated clothing of their husbands, ${ }^{2}$ and occupationally. ${ }^{3}$ This has potential acute and chronic health implications for these women.

The unregulated and indiscriminate use of pesticides in developing countries persists with the development of increasing demands for improved agricultural productivity to sustain growing populations. $^{4-6}$ The use of pesticides under these conditions by impoverished women farmers and farm workers with limited education and training ${ }^{7}$ and poor access to personal protective equipment $(\mathrm{PPE})^{7} 8$ increases their risk for acute and chronic adverse health outcomes. In the absence of appropriate safety practices during pesticide storage, mixing and application, their families and communities are also put at risk of exposure. ${ }^{4}$

In developing countries, small-scale agricultural production for subsistence or the local market

\section{What this paper adds}

- The use of pesticides in developing countries persists in the presence of illiteracy and limited safety training and practices.

- In South Africa there is little information on pesticide exposure and safety practices among women working in small-scale agriculture.

- Women working in small-scale agriculture in South Africa are exposed to pesticides during mixing and spraying.

- Women are unable to read pesticide labels, have limited access to pesticide training and observe few pesticide safety practices.

- An integrated intervention involving the government, the pesticide industry and small-scale farmers is required to assist these women achieve adequate pesticide safety.

places considerable financial constraints on farmers. Accessing pesticide training programmes and protective equipment is difficult and not normal practice $^{910}$ and so farmers have to rely on government supported initiatives which may not be forthcoming or even exist. ${ }^{11}$

South Africa is a country where pesticide use remains largely unregulated with outdated pesticide legislation. ${ }^{12}$ As part of the strategies to address apartheid era socio-economic imbalances, the government has embarked on land redistribution initiatives $^{13}$ and support of agricultural activities to increase productivity, alleviate unemployment and develop the economy. This rapid development has partly contributed to the indiscriminate use of pesticides. In addition, the legislation governing pesticide registration, distribution, worker safety and health is managed by several rather than a single ministerial department. ${ }^{12}$ Pesticide registration and sales are monitored by the Department of Agriculture, Forestry and Fisheries. ${ }^{14}$ Pesticide poisoning is a notifiable condition under the National Health Act (No 61 of 2003) regulated by the Department of Health. ${ }^{15}$ However, poisonings are severely underreported. ${ }^{11}$ The Hazardous Chemical Substances Regulations promulgated in terms of the Occupational Health and Safety Act (No 85 of 1993) ${ }^{16}$ regulated by the Department of Labour require all workers including the self-employed, who are exposed to hazardous chemicals such as pesticides to be trained regarding their occupational exposures.

Small-scale farming in various areas of South Africa is essentially self-employment. Women are increasingly participating in small-scale agriculture 
in South Africa, both as owners and workers, as men continue to seek work as migrant labourers in urban areas. Women report the use of and exposure to several hazardous pesticides. ${ }^{17} 18$ As a result they are subject to the terms of the legislation. Although provision of training is the responsibility of the employer, in small-scale farming where farm owners work alongside labourers under considerable financial constraints, implementation of occupational health and safety legislative requirements is generally unlikely.

Farm workers are among the most disadvantaged of all economically active groups in South Africa, with the majority living and working in harsh conditions, experiencing high levels of illiteracy and little awareness of employee rights. ${ }^{19} 20$ Women by virtue of their gender are further disadvantaged in agriculture. $^{18}$

Organophosphate and carbamate pesticides, some of the most hazardous pesticides women farmers and farm workers are exposed to, cause depression of acetylcholinesterase (AChe), which increases acetylcholine levels at neural junctions producing both acute and chronic adverse neurological effects. ${ }^{21} 22$ Monitoring AChe levels makes it possible to identify the acute biological effects of organophosphates and carbamates in exposed individuals, thus allowing the early identification and removal of affected workers to reduce the potential for adverse health effects. The presence of affected workers implies inadequate existing safety practices.

The report presented in this paper was part of a larger crosssectional study which sought to describe the occupational health problems of women working in small-scale agriculture on the Makhatini Flats in rural KwaZulu-Natal (KZN), South Africa. We investigated women's access to pesticide training, their safety practices and their erythrocyte AChe levels. This paper describes the training and safety practices when mixing and spraying pesticides, and AChe levels among women working in small-scale agriculture on an irrigation scheme and in the drylands of the Makhatini Flats.

\section{METHODS}

\section{Study area, population and recruitment of participants}

Details of the study area, population and recruitment of study participants have been reported in detail previously. ${ }^{17}$ In summary, the Makhatini Flats is located in northern KZN, an agriculturally intensive area consisting of small-scale farms either on an artificial irrigation scheme $(n=276 ; 1-10$ hectares in size) or in a dryland area ( $n=1200 ; 1-5$ hectares in size). Due to the temperate climate, farmers practise mixed cropping throughout the year.

Data collection occurred Monday to Friday during June, July and August in 2006. All women 18 years of age and older, working in agriculture on the Makhatini Flats were invited through farmers' unions to voluntarily participate in the interview survey administered by trained field workers in isiZulu, the local language, at 13 randomly chosen sites on the Makhatini Flats. All women present at the site on the interview days participated in the study. In the absence of a complete sampling frame, based on pre-survey visits to the study area we estimated that approximately 4400 women worked on the farms on the Makhatini Flats of whom 913 (20.8\%) participated in the study.

\section{Interview instrument and data collection}

The questionnaire was administered at the end of the working day (11:00 to $15: 00 \mathrm{~h}$ ) to study participants by trained native isiZulu-speaking field workers. ${ }^{17}$ In addition to demographic and crop production information, the questionnaire enquired about pesticide training, reading of pesticide label information, types of pesticides used, application methods, and safety practices during the mixing, application and storage of pesticides.

Responses to questions on pesticide training were categorised as 'yes' and 'no', while responses to questions on the use of pesticide label information, safety and storage practices were categorised as 'never', 'rarely', 'sometimes', 'often' and 'always'. As part of understanding safety practices, we asked about reading pesticide labels and tested participants' ability to interpret pictograms by showing them two pictograms which commonly appear on pesticide labels and asked them for an interpretation. ${ }^{23}$ When asked about waiting times before re-entry into a sprayed field, participants were given four options to choose from: '<30 min', '30 min to 4 h', ' $4 \mathrm{~h}$ to $24 \mathrm{~h}$ ' and ' $>24 \mathrm{~h}$ '.

Written consent was obtained from the participants for the interview and AChe testing, with illiterate women providing a thumb print as an indication of their consent. Prior to obtaining consent and following the questionnaire interview which took approximately $30 \mathrm{~min}$ to complete, the test procedure was explained to the participant with the option to reconsider her participation.

AChe levels were tested using the Test-mate Cholinesterase testing kit developed by EOM Research (Cincinnati, Ohio, USA). ${ }^{24}$ McConnell et al have demonstrated that the test has a small coefficient of variance and a drop in AChe level of $22 \%$ can be detected. ${ }^{25}$ A trained nurse conducted the AChe field testing. Prior to AChe testing women were asked to wash their hands with soap and water in order to prevent contamination of blood samples. The testing procedure was conducted according to the instructions detailed in the test manual. ${ }^{24}$ Since crop cultivation occurs throughout the year and farmers do not follow a uniform spraying schedule, it was not possible to establish pre-exposure AChe levels in our study population. Of the 913 women who participated in the questionnaire survey, 28 refused to have their AChe levels measured. Of the 885 women for whom AChe levels were obtained, the AChe results of 82 participants had to be discarded because of temperature extremes and procedural errors during testing. The results presented in this paper refer, therefore, to the 803 women for whom we had usable AChe results.

\section{Data analysis}

The data collected were coded and captured by trained data personnel in EPIDATA. STATA v 10 was used to analyse the data. Women who reported being the person primarily responsible for spraying pesticides on the farm were classified as 'sprayers' and women who did not spray or sprayed pesticides less than once per year were classified as 'non-sprayers'. The independent samples t test and $\chi^{2}$ test were used for continuous and categorical variables, respectively, to identify significant demographic differences between sprayers and non-sprayers. Safety practice information was available for the sprayers. During analysis the sprayers responses on pesticide information, safety practices and storage were recoded as 'never to sometimes'=no and 'often and always'=yes.

\section{Components of safety behaviour}

Fifty four variables on pesticide sources, information, safety practices and storage were subjected to principal components analysis (PCA). PCA revealed the presence of 15 components with eigenvalues exceeding 1. However, the screeplot revealed a clear break after the third component and parallel analysis confirmed the inclusion of the three components. Variables with a loading of more than 0.2 were included in each component. We 
Table 1 Demographic details of women working in agriculture

\begin{tabular}{|c|c|c|c|c|}
\hline Variable & & $\mathrm{n}=803(\%)$ & Mean & Range \\
\hline \multirow[t]{2}{*}{ Age (years) } & Sprayers & 361 (44.9) & 41.5 & $18-80$ \\
\hline & Non-sprayers & $423(52.7)$ & 42.1 & $18-82$ \\
\hline \multirow[t]{2}{*}{ Years of education } & Sprayers & $208(25.9)$ & 6.8 & $1-12$ \\
\hline & Non-sprayers & $249(31.0)$ & 7.0 & $1-12$ \\
\hline \multirow{2}{*}{$\begin{array}{l}\text { Length of residence on the } \\
\text { Makhatini Flats (years)* }\end{array}$} & Sprayers & $350(43.6)$ & 25.6 & $1-80$ \\
\hline & Non-sprayers & $404(50.3)$ & 23.2 & $1-76$ \\
\hline \multirow{2}{*}{$\begin{array}{l}\text { Years spent working } \\
\text { in agriculture* }\end{array}$} & Sprayers & $253(31.5)$ & 8.5 & $1-37$ \\
\hline & Non-sprayers & $283(35.2)$ & 7.1 & $1-50$ \\
\hline
\end{tabular}

assessed safety behaviour among the sprayers using the median of the principal components' score as a cut-off point. The $\chi^{2}$ was used to test for significant differences in safety behaviour between women working on the irrigation scheme and in the drylands. The accepted level of significance was $0.05(\boldsymbol{\alpha}=0.05)$.

Full ethics approval for this study was obtained from the Biomedical Research Ethics Committee of the University of KwaZulu-Natal.

\section{RESULTS \\ Demographic profile}

Although the mean age (41.8 years; range: $18-82$ years) of the participants indicated mature adulthood, some participants were young adults. Reflecting the socioeconomic status of this group of women, 204 (25.4\%) had never attended school, while among those who did attend school the mean years of education were 6.9 years (range: $2-12$ ). Mean length of residence in the study area was 24.3 years (range: $1-80$ years) (table 1 ).

Among the 803 study women, 366 (45.6\%) were the primary sprayers on their farm. Among those women who did not spray $(n=437)$, the majority used either a family member $(n=173$; $39.6 \%)$ or hired a sprayer $(n=107 ; 24.5 \%)$. In the remaining cases, for $55(12.6 \%), 17(3.9 \%)$ and $5(1.1 \%)$, spraying was done by a co-worker, the farm owner or a neighbour, respectively. Eighty (18.3\%) respondents did not know who was responsible for pesticide application.

Significantly more sprayers ( $\mathrm{n}=332 ; 90.8 \%$ ) compared to nonsprayers ( $n=303 ; 69.3 \%$ ) lived on farms which either they or their families owned $(p<0.001)$.

\section{Sources of pesticides, information and training}

Women who sprayed their own pesticides $(n=366)$ were questioned further on their sources of pesticides used, information and training received. Most women purchased their own pesticides ( $n=282 ; 77.1 \%$ ) as opposed to receiving supplies from a third party. Third party sources included family members $(\mathrm{n}=43 ; 11.8 \%)$, the farm owner $(\mathrm{n}=19 ; 5.2 \%)$, a neighbour $(\mathrm{n}=15 ; 4.1 \%)$ and the Agricultural Research Council $(\mathrm{n}=7$; $1.9 \%)$.

Of the women who purchased their own pesticides, 48 $(17.0 \%)$ reported purchasing their pesticides from more than one pesticide sales source. These pesticide sales sources included the local co-operative on the Makhatini Flats ( $\mathrm{n}=313$; $85.5 \%$ ), a cooperative located in Pongola $(n=38 ; 10.4 \%)$ approximately $200 \mathrm{~km}$ away from the study site, the local supermarket $(\mathrm{n}=16$; $4.4 \%)$ and a salesperson from a pesticide company $(n=9 ; 2.5 \%)$.

When questioned about 'sources of pesticide information', 105 $(28.7 \%)$ women reported receiving no pesticide information at all, $183(50.0 \%)$ received their pesticide information from a single source and $78(21.3 \%)$ received pesticide information from multiple sources. Agricultural extension officers (AEOs) were the most common source of pesticide information $(n=128$; $34.9 \%$ ). The second most common source of pesticide information were pesticide salespersons ( $n=80 ; 21.9 \%$ ).

Sixty $(16.4 \%)$ women had ever attended a training course on pesticides. The median number of courses attended was two (range: $1-12$ ). Nearly a quarter of these women ( $n=16 ; 26.7 \%$ ) could not remember who had trained them. The others received training from the Department of Agriculture, Forestry and Fisheries ( $n=13 ; 21.7 \%)$, Makhatini co-operative $(n=13 ; 21.7 \%)$, Mjindi Cotton, a parastatal organisation ( $n=8 ; 13.3 \%)$, fellow farmers $(n=7 ; 11.7 \%)$ and the Agriculture Research Centre $(\mathrm{n}=3,5.0 \%)$

\section{Safety practices during pesticide mixing and application}

The safety practices during pesticide mixing and application described below refer to the women $(n=366)$ who sprayed their own pesticides.

\section{Reading pesticide labels}

Only $85(23.2 \%)$ of the women could read English and 69 $(18.9 \%)$ reported ever reading the pesticide labels. Sixty five women $(17.8 \%)$ read the label for mixing instructions and the correct crops to spray, $62(16.9 \%)$ for precautions to take and 59 (16.1\%) for possible health consequences from exposure. When shown the pictograms, 64 (17.5\%) women correctly interpreted the 'keep locked away and out of reach of children' pictogram and 95 (25.9\%) women correctly interpreted the second pictogram 'wash after use'. Women who had ever attended a pesticide training course were significantly more likely to correctly identify the pictograms as compared to women who had never been trained $(p=0.02)$. Women who correctly interpreted the 'keep locked away and out of reach of children' pictogram were significantly more likely to report locking up pesticides as compared to women who failed to correctly interpret the pictogram $(p=0.01)$. However, there was no significant difference with respect to the practice of hand washing after mixing pesticides among women who correctly or incorrectly interpreted the 'wash after use' pictogram.

\section{Safety practices when mixing and applying pesticides}

Twenty $(5.5 \%)$ of the sprayers $(n=366)$ did not mix pesticides, as this was done by the farm owner, while 346 (94.5\%) mixed and applied pesticides themselves. The majority of women $(n=322$; 93.1\%) mixed pesticides outdoors. In total, 329 (95.1\%) women reported measuring pesticides when mixing, of whom, 134 $(38.7 \%)$ and 131 (37.9\%) reported using a scale and their hands, respectively, to measure the pesticides. Most women $(n=211$; $60.9 \%$ ) mixed their pesticides directly in the knapsack spray container. Women on the irrigation scheme were significantly more likely to mix their pesticides in the knapsack spray container $(p=0.01)$, while dryland women were significantly more likely to mix pesticides in a bucket $(p=0.01)$ as compared to their counterparts.

When applying pesticides, the majority of women $(n=340$, $92.9 \%$ ) used a manual knapsack pesticide applicator, while the remaining women used their bare hands $(n=12 ; 3.3 \%)$, brooms $(n=8 ; 2.2 \%)$, diesel operated knapsacks $(n=4 ; 1.1 \%)$ and buckets $(\mathrm{n}=2 ; 0.6 \%)$.

When mixing and applying, 196 (56.7\%) and 201 (54.9\%) women, respectively, reported using some form of PPE. The PPE most frequently used was boots followed by coats and overalls. Gloves, masks and eye protection were less frequently reported 
Table 2 Safety practices during pesticide mixing and application

\begin{tabular}{|c|c|c|c|}
\hline \multicolumn{2}{|l|}{ Mixing } & $\frac{\text { Irrigation scheme }}{n=116(\%)}$ & $\begin{array}{l}\text { Drylands } \\
\mathrm{n}=230(\%)\end{array}$ \\
\hline \multirow[t]{2}{*}{ Site of mixing pesticides } & Outdoors & $110(94.8)$ & $212(92.2)$ \\
\hline & Indoors & $6(5.2)$ & $18(7.8)$ \\
\hline \multirow[t]{4}{*}{ Method of measuring pesticides } & Scale & $40(34.5)$ & $94(40.9)$ \\
\hline & Bare hands & $51(43.9)$ & $80(34.8)$ \\
\hline & Measuring cup & $19(16.4)$ & $30(13.0)$ \\
\hline & Hand-made scoop $†$ & $2(1.7)$ & $12(5.2)$ \\
\hline \multirow[t]{2}{*}{ Method of mixing pesticides } & In back pack applicator* & $82(70.7)$ & $129(56.1)$ \\
\hline & In bucket* & $34(29.3)$ & $101(43.9)$ \\
\hline \multirow[t]{5}{*}{ Use of PPE when mixing } & Boots** & $79(68.1)$ & $78(33.9)$ \\
\hline & Coats/overalls & $34(29.3)$ & $63(27.4)$ \\
\hline & Gloves & $23(19.8)$ & $46(20.0)$ \\
\hline & Dust masks & $18(15.5)$ & $27(11.7)$ \\
\hline & Eye goggles & $4(3.4)$ & $16(6.9)$ \\
\hline \multicolumn{2}{|l|}{ Spraying } & $n=126(\%)$ & $\mathrm{n}=240(\%)$ \\
\hline \multirow[t]{5}{*}{ Method of pesticide application } & Manual back pack applicator & $119(94.4)$ & $221(92.1)$ \\
\hline & Bare hands & $1(0.8)$ & $11(4.6)$ \\
\hline & Broom & $3(2.4)$ & $5(2.1)$ \\
\hline & Diesel operated back pack applicator & $2(1.6)$ & $2(0.80)$ \\
\hline & Bucket & $1(0.8)$ & $1(0.4)$ \\
\hline \multirow[t]{5}{*}{ Use of PPE when spraying } & Boots** & $85(67.5)$ & $77(32.8)$ \\
\hline & Gloves & $21(16.7)$ & $45(18.8)$ \\
\hline & Coats/overalls & $36(28.6)$ & $59(24.6)$ \\
\hline & Masks & $18(14.3)$ & $28(11.7)$ \\
\hline & Eye goggles & $4(2.8)$ & $15(6.3)$ \\
\hline \multicolumn{2}{|c|}{ Prevalence of components of safety behaviour among sprayers } & $n=126(\%)$ & $n=240(\%)$ \\
\hline \multicolumn{2}{|r|}{$\begin{array}{l}\text { Frequency of/reasons for reading } \\
\text { pesticide labels* } \neq\end{array}$} & $72(57.1)$ & $111(46.3)$ \\
\hline \multicolumn{2}{|r|}{ Use of personal protective equipment $\S$} & $65(51.6)$ & $118(49.2)$ \\
\hline \multicolumn{2}{|r|}{ Sources of pesticide information* } & $71(56.4)$ & $112(46.7)$ \\
\hline
\end{tabular}

by the women. Women on the irrigation scheme were significantly more likely to use boots when mixing $(p<0.001)$ and spraying $(p<0.001)$ as compared to women in the drylands (table 2).

The respondents were asked about the presence of workers in the field during pesticide application. Fifteen women (4.1\%) worked alone. Seventy seven $(21.0 \%)$ women indicated that workers were present in the field when application took place, while the majority of women $(n=274 ; 74.9 \%)$ indicated that no workers were present in the fields when application took place.

In total, 289 women (78.9\%) (including those who worked alone) followed waiting periods of varying duration after pesticide application before returning to the fields. Approximately $82.4 \%(n=238)$ of the 289 applicators waited more than $24 \mathrm{~h}$, while $15.2 \%(n=44), 1.4 \%(n=4)$ and $1.0 \%(n=3)$ waited more than $4 \mathrm{~h}$ but less than $24 \mathrm{~h}$, less than $4 \mathrm{~h}$, and less than $30 \mathrm{~min}$, respectively.

\section{Storage safety, personal hygiene and practice}

The majority of women $(n=162 ; 44.3 \%)$ reported storing pesticides outside in the open (either in the vicinity of their home or their fields), while 155 (42.4\%) stored pesticides in a special room outside their home set aside for pesticides, and 49 $(13.4 \%)$ stored pesticides inside their home. Forty $(10.9 \%)$ reported locking up the pesticides.
The majority of women who mixed $(n=346)$ pesticides reported washing their hands after mixing ( $n=343 ; 99.1 \%$ ) and of these 294 (84.9\%) reported using soap to wash their hands. A limited number of women reported washing their PPE $(n=167$; $45.6 \%$ ), of whom 162 (44.3\%) used soap and water to wash their PPE.

Twelve (3.3\%), 7 (1.9\%) and $2(0.6 \%)$ women reported storing their pesticides with clothing, food and water, respectively. Eighteen (4.9\%) and $13(3.6 \%)$ women, respectively, reported using empty pesticide containers to carry water and wash clothing. Fifteen (4.1\%) and $13(3.6 \%)$ women, respectively, reported using the empty containers to burn paper and plastic. Among the remaining 307 women, 171 (55.6\%) burnt the containers, $72(23.6 \%)$ buried the containers, $43(13.9 \%)$ threw the containers away with domestic waste and 21 (6.9\%) reused the containers for pesticides.

\section{Safety behaviour principal components}

Three principal components were identified, each relating to an aspect of safety behaviour. In the first component variables loaded on the "frequency of and reasons for reading pesticide labels' loaded, the second on 'use of personal protective equipment' during mixing and spraying of pesticides and the third component on 'sources of pesticide information'. The prevalence of the three components was higher among women on the 
Table 3 Comparison of acetylcholinesterase (AChe) levels between studies among exposed and non-exposed populations

\begin{tabular}{|c|c|c|c|c|c|c|}
\hline \multirow[b]{2}{*}{ Study } & \multirow[b]{2}{*}{ Location } & \multirow[b]{2}{*}{ Study population gender } & \multicolumn{2}{|c|}{ Exposed } & \multicolumn{2}{|c|}{ Unexposed } \\
\hline & & & $\mathrm{n}$ & AChe (U/g Hb) & $\mathrm{n}$ & AChe $(\mathrm{U} / \mathrm{g} \mathrm{Hb})$ \\
\hline Current study (Makhatini Flats)* & South Africa & Female & 366 & 29.3 & 437 & 28.6 \\
\hline Gomes et $a l^{33}$ & United Arab Emirates & Not stated & 532 & 29.9 & 532 & 32.1 \\
\hline Ciesielski et $a l^{34}$ & United States of America & Mixed (male predominance) & 202 & 30.2 & 42 & 32.2 \\
\hline
\end{tabular}

*In this study population: 'exposed' refers to sprayers and 'unexposed' to non-sprayers.

irrigation scheme as compared to those in the drylands, with significant differences with respect to 'frequency/reasons for reading pesticide information' ( $\mathrm{p}=0.03$ ) and 'sources of pesticide information' ( $p=0.05$ ) (table 2 ).

\section{Reported organophosphate use and AChe levels}

Of the 803 women, 251 (31.3\%) could recall the names of the pesticides which they used, with $91(11.3 \%)$ reporting the use of organophosphates on their crops. Sixty seven (8.3\%) reported spraying pesticides in the past month, of whom only $19(2.4 \%)$ sprayed organophosphates. The organophosphate compounds women reported using were monocroptophos, methamidaphos, mercaptothion and dimethoate. There were significant differences between sprayers and non-sprayers with respect to recalling pesticide names $(43.4 \%$ vs $21.1 \%$; $<<0.001)$, the use of organophosphates $(19.4 \%$ vs $4.6 \% ; \mathrm{p}<0.001)$, the mean frequency with which their fields were sprayed each year (11.7 vs $6.3 ; \mathrm{p}<0.001)$ and the mean duration of the spraying (5.1 $\mathrm{h}$ vs $3.5 \mathrm{~h} ; \mathrm{p}=0.03$ ).

The mean AChe corrected for haemoglobin among all study participants was $28.9 \mathrm{U} / \mathrm{g} \mathrm{Hb}$ (95\% CI 28.4 to 29.4). The mean AChe levels corrected for haemoglobin among non-sprayers and sprayers were $29.3 \mathrm{U} / \mathrm{g} \mathrm{Hb}$ (95\% CI 28.4 to 30.3) and $28.6 \mathrm{U} / \mathrm{g}$ $\mathrm{Hb}(95 \%$ CI 28.1 to 29.1$)$, respectively.

\section{DISCUSSION}

Our results indicate that women working in small-scale agriculture in rural $\mathrm{KZN}$ have limited access to pesticide training and observe few safety practices when mixing, spraying and storing pesticides. As was the case with other studies in developing countries, ${ }^{326}$ only a few women in our study had received formal training on pesticide use and safety. This lack of training was reflected in the few women who actually read pesticide labels and could correctly interpret safety pictograms. ${ }^{23}$ This problem is compounded by the low literacy ${ }^{17}$ rates in this population and the fact that pesticide labels are predominantly printed in English and Afrikaans and not in the local language (isiZulu). Despite the low levels of literacy, it was previously reported that women on the irrigation scheme were significantly better educated than their dryland counterparts ${ }^{17}$ and were more likely to read and cite reasons for reading pesticide labels. This could account for the significant difference between the two groups of women with respect to the use of boots when mixing and spraying pesticides and the prevalence of the principal components of safety behaviour seen in this study.

Our study found that women did not have the correct equipment to measure, mix or apply pesticides, often using their hands instead for such purposes. Similarly, a limited number of women used PPE when mixing and spraying pesticides and very few locked up their pesticides when not in use. Such practices put these women at high risk for adverse acute and chronic pesticide related health effects which have been well documented in the literature. ${ }^{72728}$ Reproductive, neurological and carcinogenic effects known to be associated with pesticides are likely to compound existing health problems such as HIV infections in this community, having economic and social consequences for farmers. Ill farmers unable to work will not be able to contribute to household income and where mortality ensues households headed by orphans may be the consequence.

Failure to lock up pesticides allows access by children and other family members, which has been known to result in adverse events. $^{28}$ Despite the small number of women who reported storing pesticides with food and domestic reuse of pesticide containers, this practice does exist and further increases the potential for domestic exposure to pesticides among family members. Lack of finances, ${ }^{9}{ }^{10}$ discomfort with PPE and slowing of work ${ }^{29}$ have been cited in the literature as reasons for the absence and non-use of PPE and these are most likely reasons in our study population as well. Poverty levels are high in rural communities in South Africa with more than $78 \%$ of available household income prioritised for needs such as food, utilities, clothing and transport. ${ }^{30}$ As a result limited finances are available for the purchase of PPE. In addition, temperatures can rise above $30^{\circ} \mathrm{C}$ in the Makhatini Flats which would also make using PPE very uncomfortable.

This report is one of the very few published studies to present the results of AChe measurements in a population composed exclusively of women. We tested AChe levels in our study population of 803 women but were unable to show any significant differences in AChe levels corrected for haemoglobin between sprayers and non-sprayers (see online table). Factors which may account for this in our study population include the small number of women who reported spraying organophosphates $(2.4 \%)$ and spraying pesticides in the past month $(8.3 \%)$, the high percentage of women $(82.4 \%)$ who report waiting only $24 \mathrm{~h}$ before returning to the fields after pesticide application, and the absence of either a uniform spray schedule or a clearly defined period of non-exposure among the women. In addition, women may have had exposure to organophosphates via other routes such as domestic and environmental contamination. Domestic exposure occurs because women are responsible for washing pesticide contaminated clothing ${ }^{2}$ and they may consume pesticide contaminated foods. Analysis conducted in the area has shown water contaminated with agricultural insecticides. ${ }^{31}$ The field testing method employed may also have been a limiting factor in this study as London et al in the Western Cape province of South Africa have shown that the test kit, while having high levels of reproducibility, has limited validity which may influence its use in cross-sectional testing. ${ }^{32}$ With a cross-sectional study design, comparisons on exposure may be weaker and subject to bias. The mean AChe levels corrected for haemoglobin in exposed and non-exposed workers in our study were between 3 and $4 \mathrm{U} / \mathrm{g} \mathrm{Hb}$ among sprayers and 1 and $3 \mathrm{U} / \mathrm{g} \mathrm{Hb}$ among non-sprayers, which are lower than those measured in other studies. The latter reasons, particularly the 
exclusive female character of our sample, accounts for the AChe findings in our study being at variance with others reported in the literature (table 3). ${ }^{22} 3334$

The South African government actively encourages smallscale farmers, raising expectations among these farmers of achieving levels of commercial viability. ${ }^{12}$ As a result these expectations may have fuelled the excessive and inappropriate use of pesticides. ${ }^{17}$ The government has to introduce a policy which has a twofold approach of regulating pesticide sale and use with a view to implementing restrictions and moving towards banning WHO Hazardous Class I a/b pesticides, ${ }^{35}$ and promoting programmes which encourage sustainable agriculture. $^{36}$ One way of restricting pesticide sales is to ensure that only farmers who have a certificate confirming pesticide safety training by an AEO can purchase pesticides. In addition, methods of integrated pest management (IPM) should be taught to farmers by AEOs concurrently with pesticide safety. Furthermore, the government should introduce support programmes such as financial aid for small-scale farmers who choose to adopt IPM methods and decrease pesticide use. The government could also set up links with urban markets orientated towards the sale of pesticide free foods through which small-scale farmers can sell their produce.

\section{CONCLUSION}

Women working in small-scale agriculture in rural KZN with limited access to pesticide training are at risk for acute and chronic adverse pesticide related health effects and unknowingly contribute to environmental contamination. An integrated effort by the government is required to assist small-scale farmers achieve adequate pesticide safety thus averting acute and chronic adverse health effects, while concurrently encouraging cost-effective IPM strategies reducing pesticide use.

Acknowledgements The authors would like to thank the farmers' unions and women of the Makhatini Flats who supported and participated in the study. We are also grateful to S Mnyaiza and C Memela for managing data collection in the field.

Funding This study was funded by the South African Netherlands Research Programme on Alternatives in Development (SANPAD) and the South African Medical Research Council (SA MRC)

Competing interests None

Ethics approval This study was conducted with the approval of the University of KwaZulu-Natal.

Provenance and peer review Not commissioned; externally peer reviewed.

\section{REFERENCES}

1. International Labour Organisation. Global employment trends for women: March 2009. Geneva: International Labour Office, 2009.

2. Rao $\mathbf{P}$, Gentry AL, Quandt SA, et al. Pesticide safety behaviors in Latino farmworker family households. Am J Ind Med 2006;49:271-80.

3. Atreya K. Pesticide use knowledge and practices: a gender differences in Nepal. Environl Res 2007;104:305-11.

4. Ecobichon DJ. Pesticide use in developing countries. Toxicology 2001;160:27-33

5. Mansour SA. Pesticide exposure - Egyptian scene. Toxicology 2004;198:91-115

6. Smith C, Kerr K, Sadripour A. Pesticide exports from U.S. ports 2001-2003. Int J Occup Environ Health 2008;14:176-86.

7. Jors E, Morant RC, Aguilar GC, et al. Occupational pesticide intoxications among farmers in Bolivia: a cross-sectional study. Environ Health 2006;5:10.
8. Sekiyama M, Tanaka M, Gunawan B, et al. Pesticide usage and its association with health symptoms among farmers in rural villages in West Java, Indonesia. Environ Sci 2007; 14:23-33.

9. Palis FG, Flor RJ, Warburton $\mathrm{H}$, et al. Our farmers at risk: behaviour and belief system in pesticide safety. J Public Health 2006;28:43-8.

10. Hanshi JA. Use of pesticides and personal protective equipment by applicators in a Kenyan district. African Newsletter on Occupational Health and Safety 2001;11:74-6

11. London L, Bailie R. Challenges for improving surveillance for pesticide poisoning: policy implications for developing countries. Int J Epidemiol 2001;30:564-70.

12. Rother HA, Hall R, London L. Pesticide use among emerging farmers in South Africa: contributing factors and stakeholder perceptions. Development Southern Africa 2008;25:399-424.

13. Hall R. A political economy of land reform in South Africa. Review of African Political Economy 2004;31:213-27.

14. Department of Agriculture, Forestry and Fisheries. Fertilizers, Farm Feeds, Agricultural Remedies and Stock Remedies Act, (Act No. 36 of 1947). Pretoria.

15. Department of Health. National Health Act, (Act No. 61 of 2003). Pretoria.

16. Department of Labour. Regulations for Hazardous Chemical Substances Occupational Health and Safety Act (Act No. 85 of 1993). Pretoria.

17. Naidoo S, London L, Burdorf A, et al. Agricultural activities, pesticide use and occupational hazards among women working in small scale farming in Northern KwaZulu-Natal, South Africa. Int J Occup Environ Health 2008;14:218-24.

18. London L, de Grosbois S, Wessling C, et al. Pesticide usage and health consequences for women in developing countries: out of sight, out of mind? Int $J$ Occup Environ Health 2002;8:46-59.

19. Robins T, Salie F, Gwagwa T. Occupational hazards, living conditions, and physica assault of sugar cane workers in KwaZulu-Natal, South Africa. S Afr Med J 1998;88:1117-27.

20. London L, Nell V, Thompson ML, et al. Health status among farm workers in the Western Cape-collateral evidence from a study of occupational hazards. South Africa. S Afr Med J 1998;88:1096-101.

21. Wessling $\mathbf{C}$, Keifer M, Alhbom A. Long-term neurobehavioral effects of mild poisonings with organophosphate and n-methyl carbamate pesticides among banana workers. Int J Occup Environ Health 2002;8:27-34.

22. Ngowi AV, Maeda DN, Partanen TJ, et al. Acute health effects of organophosphorus pesticides on Tanzanian small-scale coffee growers. J Expo Anal Environ Epidemio 2001:11:335-9.

23. Rother H-A. South African farm workers' interpretation of risk assessment data expressed as pictograms on pesticide labels. Environ Res 2008;108:419-27.

24. EOM and Research. Test-mate che cholinesterase test system (model 400). Instruction manual. Cincinnati. OH. USA: EQM Research Inc (Manual-E). 2003:1-31.

25. McConnell R, Cedillo L, Keifer M, et al. Monitoring organophosphate insecticideexposed workers for cholinesterase depression. New technology for office or field use. J Occup Med 1992;34:34-7.

26. Ibitayo 00. Egyptian farmers' attitudes and behaviors regarding agricultural pesticides: implications for pesticide risk communication. Risk Anal 2006;26:989-95.

27. Mancini F, Van Bruggen AH, Jiggins JL, et al. Acute pesticide poisoning among female and male cotton growers in India. Int J Occup Environ Health 2005; 11:221-32.

28. Cantor A, Young-Holt B. Pesticide-related symptoms among farm workers in rural Honduras. Int J Occup Environ Health 2002;8;41-5.

29. Forst L, Noth IM, Lacey $S$, et al. Barriers and benefits of protective eyewear use by latino farm workers. J Agromedicine 2006:11;11-17.

30. Statistics South Africa. Income and expenditure of households 2005/2006: analysis of results. Pretoria: Statistics South Africa 2007.

31. Sereda BL, Meindhardt. Contamination of the water environment in malaria endemic areas of KwaZulu-Natal, South Africa by agricultural insecticide. Bull Environ Contam Toxicol 2005;75:530-7.

32. London L, Thompson ML, Sacks $S$, et al. Repeatability and validity of a field kit for estimation of cholinesterase in whole blood. Occup Environ Med 1995;52:57-64.

33. Gomes J, Lloyd 0, Revitt DM, et al. Erythrocyte cholinesterase activity levels in desert farm workers. Occup Med 1997:47:90-4.

34. Ciesielski S, Loomis DP, Mims SR, et al. Pesticide exposures, cholinesterase depression, and symptoms among North Carolina migrant farmworkers. Am J Public Health 1994;84:446-51.

35. World Health Organization (WHO). The WHO recommended classification of pesticides by hazard and guidelines to classification. Geneva, Switzerland: WHO 2004.

36. Pretty J. Agricultural sustainability: concepts, principles and evidence. Philos Trans $R$ Soc Lond B Biol Sci 2008:363:447-65. 